\title{
INVESTIGAÇÃO DE ENFERMAGEM SOBRE O USO DE CATETERES VENOSOS EM CLIENTES HOSPITALIZADOS
}

NURSING RESEARCH ON INTRAVENOUS CATHETERISATION FOR HOSPITALISED PATIENTS.

\author{
Iwa Keiko Aida Utyama ${ }^{1}$ \\ Mitsuko Ohnishi ${ }^{1}$ \\ Regina Mariuza Borsato Quesada ${ }^{2}$ \\ Cassia Hitomi Ishioka ${ }^{3}$
}

RESUMO: Através do presente estudo pode-se concluir que a cateterização intravenosa foi efetuada em $59,4 \%$ da amostra por acesso venoso dificultado; em $100 \%$ da amostra foi efetuado curativo fechado, sendo que a troca do curativo foi feita a cada 48 horas em $89,8 \%$ da amostra; o tempo de permanência do cateter intravenoso foi de até 10 dias em $52 \%$ dos casos, sendo que o cateter foi retirado em $34,8 \%$ por suspensão da medicação e problemas técnicos, respectivamente. $O$ microrganismo de maior incidência foi Staphylococcus aureus em $20,3 \%$ da amostra analisada.

UNITERMOS: Cateter venoso - Venossecção - Punção percutânea Cultura de cateter.

ABSTRACT: This report shows that intravenous catheterisation has been required for $59.4 \%$ of the patients in this sample. The main reason identified for catheterisation was the difficulty in accessing peripheral veins. The wound dressing was applied for $100 \%$ of the patients and the procedure itself was carried out each 48 hours in $89.8 \%$ of them. The intravenous catheter stood for 10 days in $52 \%$ of the cases and it was removed in $34.8 \%$ for intravenous drugs interruption and the other reasons were related as to technical problems. The most present microorganism was Staphylococcus aureus in $20.3 \%$ of the catheter cultures.

KEYWORDS: Intravenous catheter - Venesection - Percutaneous puncture Catheter culture.

\footnotetext{
${ }^{1}$ Docentes do Departamento de Enfermagem, CCS-UEL

2 Docente do Departamento de Patologia Aplicada, Legislação e Deontologia, CCS-UEL

${ }^{3}$ Discente do Curso de Enfermagem do CCS-UEL
} 


\section{INTRODUÇÃO}

No início do século XIX, o avanço da tecnologia na área da saúde permitiu o progresso das técnicas de infusões venosas, desde a terapia parenteral com utilização de soluções estéreis até o desenvolvimento de dispositivos de administração, ou seja, catéteres especiais e agulhas segundo Bennett ${ }^{2}$.

Soares \& Oliveira ${ }^{13}$ referem que, em 1949, obtiveram acesso à veia profunda através da punção da veia subclávia; a partir desta técnica esta veia passou a ser utilizada amplamente na área da medicina para infusão de soluções para hidratação, alimentação parenteral e medida de pressão venosa central.

Entretanto, Bennett ${ }^{2}$ e Maki et al ${ }^{11}$ citam que vários autores colocam que as complicações infecciosas dos acessos venosos centrais inseridos por punção percutânea ou dissecção (flebotomia) implicam na fonte de infecção do doente. Ainda citam que a maioria das infecções relacionadas aos acessos venosos centrais iniciam com infecções locais do curativo da punção do catéter venoso causadas por microorganismos da própria flora cutânea.

Sabendo-se que a capacidade de cicatrização dos ferimentos é um processo fisiológico inerente a todo organismo vivo, destinado à reparação dos tecidos lesados como citam Koch ${ }^{9}$ e Davis ${ }^{3}$, alguns autores referem que numerosas experiências mostram que não há uma substância conhecida para uso tópico ou geral que acelere a cicatrização fisiológica normal.

Fuerst \& $W_{\text {olff }}{ }^{6}$, referem que as respostas do corpo às lesões e ao processo de cicatrização são ambos mecanismos de proteção normais e a ciência moderna não descobriu nenhuma maneira de melhorá-los; no entanto, são usados diferentes agentes terapêuticos, porém nenhum é suficiente por isso. Ainda os mesmos afirmam que a cicatrização é melhor estimulada mediante um bom funcionamento fisiológico de todo o organismo e tem sido comprovado que as feridas curam com maior rapidez quando o paciente goza de equilíbrio eletrolítico, de adequada nutrição e repouso e acrescentam que algumas atitudes podem ser tomadas para ajudar ou dar apoio a estes mecanismos, realizando curativo com técnica asséptica, troca regular dos curativos.

Duarte et al $^{4}$ sugere que a infecção do catéter venoso ocorre a partir de microorganismos provenientes da pele; portanto deve-se realizar o curativo com 
finalidade de prevenir a contaminação das feridas e reduzir a infecção sobre a ferida, como citam Kozier ${ }^{10}$ e Dugas $^{5}$

Diante de todas as considerações dos autores, surge uma série de questionamentos sobre as metodologias utilizadas para se diagnosticar que a principal fonte de infecção do paciente seja por punções percutâneas ou dissecções venosas.

O presente estudo tenı como objetivo verificar se as colocações dos autores acima citados sobre as complicações infecciosas são corretas, questionando o tipo de venossecção, sexo, idade, tempo de permanência, motivo de cateterização, motivo da retirada, incidência e classificação dos microrganismos.

\section{METODOLOGIA}

A amostra será constituída pelos pacientes de ambos os sexos, com catéter intravenoso (intracater e flebotonia), internados nas seguintes unidades: médicocirúrgico, tisiologia e semi-intensivo do Hospital Universitário da Região Norte do Paraná ( HURNP), em Londrina - Pr.

A amostra é constituída de 26 pacientes e a coleta efetivada no período de janeiro a dezembro de 1995 , através dos prontuários dos pacientes. A tabulação dos dados foi efetuada manualmente.

\section{RESULTADOS E DISCUSSÃO}

De acordo com o sexo, pode-se verificar que o masculino se destacou com $54 \%$ e o feminino com $46 \%$.

Em relação à idade, a maior incidência ficou para os individuos acima de 61 anos, com $38,5 \%$. Levou-se em consideração a deficiência imunológica do indivíduo idoso e a demora em processos de cicatrização por déficit nutricional.

O tipo de venossecção mais utilizado encontrado nas investigações foram as flebotomias, com um total de $26 \%$, e intracater, $17 \%$, isto porque alguns pacientes tiveram a necessidade dos dois tipos de venossecção para alimentação parenteral e verificação de pressão venosa central.

O tempo de permanência da flebotomia foi de 6 a 10 dias $(34,6 \%)$ e 26 a 30 dias (15,4\%); intracater, 6 a 10 dias $(41,2 \%)$ e 11 a 15 dias $(20,4 \%)$. De acordo 
com bibliografias, constatou-se que o prazo ideal seria de 9 a 10 dias para a retirada do catéter. Pode-se verificar que o motivo da cateterização mais usado era para infusão venosa, com $37,2 \%$, dentro da nutrição parenteral, antibioticoterapia e verificação do PVC; perda de catéter - $32,5 \%$, levando-se em consideração a excessiva manipulação do catéter pelos profissionais da equipe de saúde e também do paciente.

Motivos da retirada por suspensão da medicação ou infiltração - 27,9\%. Acredita-se ocorrer por tracionamento do catéter decorrente da realização inadequada do curativo e infecção - $23,3 \%$, sendo o microorganismo mais encontrado Staphylococcus aureus (23,5\%) e Acynetobacter carboacétius $(17,6 \%)$.

Nota-se, de acordo com bibliografias, que o crescimento das infecções estafitocócicas nos hospitais se dá na maioria das vezes pelo relaxamento dos procedimentos assépticos; o excesso de confiança nos antibióticos e o seu uso inadequado leva à resistência do indivíduo. A infecção causada pelo Acynetobacter carboacéticus faz acreditar-se que o pessoal da área hospitalar é o principal reservatório das infecções, pois é uma bactéria Gram (-) não fermentada e que cresce principalmente em ambiente hospitalar.

\section{CONCLUSÃO}

Através dos dados encontrados no presente estudo, conclui-se que o alto indice de infecção em pacientes com venossecção foram pela bactéria Staphylococcus aureus como já foi visto na discussão. Acredita-se que isto se dá pela excessiva manipulação e inadequada técnica asséptica utilizada pela equipe durante a realização de procedimentos ligados ao catéter, como falta de conscientização da equipe, levando à contaminação dos catéteres intravenosos e a possiveis complicações.

A própria bactéria Staphylococcus aureus é uma Gram (+) distribuída pela pele e mucosa do homem e animais; causa grande número de infecções no homem e vai depender do número e da via de introdução de seus produtos tóxicos e da exposição prévia ao microorganismo.

Considerando-se as colocações acima relacionadas à conscientização da equipe de saúde na utilização da técnica asséptica desde a instalação, curativo e 
retirada do catéter, não deixando de lado a saúde geral e o estado nutricional do indivíduo, chega-se à infecção endógena.

\section{BIBLIOGRAFIAS}

1. BAUER, Liliane et al. Flora cutânea: fonte de contaminação de cateteres venosos centrais? In: CONGRESSO BRASILEIRO DE ENFERMAGEM, 41, 1989, Florianópolis-SC. 1989. Programa. Florianópolis: Editora da UFSC, 1989.

2. BENNETT, P. J. Use of intravenous catheters. Medical Memoranda. Brit.Med.J. , v. 2, p. 1252, 1963.

3. DAVIS, Loyal. Chistopher. Clínica cirúrgica. 7. ed. Rio de Janeiro: Guanabara Koogan, 1961. p. 21 - 40.

4. DUARTE, E. R. M. et al. O que o enfermeiro deve saber sobre o curativo. In:CONGRESSO BRASILEIRO DE ENFERMAGEM, 41, 1989, Florianópolis - SC. Programa. Florianópolis: Editora da UFSC, 1989.

5. DUGAS,K. Enfermagem prática. 3 ed. Rio de Janeiro: Interamericana, 1978.

6. FUERST, E. \& WOLFF, L. U. Fundamentos de enfermagem. 5. ed. Rio de Janeiro: Interamericana, 1974.

7. HADDAD,M. C. et al. Praticidade e eficiência das ações de enfermagem nos curativos de sondas, drenos e cateteres. In: CONGRESSO BRASILEIRO DE ENFERMAGEM, 36,1984, Belo Horizonte- MG. Programa. Belo Horizonte: 1984.

8. HOWES, E. L. et al. Retardation by cortisone of woond healing. Surgery. p. 177, 1950.

9. KOCK, R. M. tratamento de feridas - princípios e cuidados de enfermagem. Novas Dimensões. São Paulo, v. 3, n. 1., p. 42-45, 1977.

10. KOZIER, D. Tratado de Enfermagem Prática. México: Interamericana, 1970. 
11. MAKI, D. G. et al. Infection control intravenous therapy. Ann. Intern. Med., v. 79, p. 876-887, 1973.

12. ROBAZZI, M. L. et al. Cateteres intravenosos-estudo de condições bacteriológicas e avaliação da assistência de enfermagem. R. Bras. Enferm. Brasilia, v.37, n.1, p. 18-25, 1984.

13. SOARES NETTO, J.J. ; OLIVEIRA, J.R. Cateterização percutânea da veia subclávia: análise e procedimentos do método. Enf. Novas Dimensões, São Paulo, v. 2, n. 6, p. 327-329. dez., 1976. 